\title{
A GAMIFICAÇÃO APLICADA À FORMAÇÃO INICIAL DE PROFESSORES DE FÍSICA EM TRÊS OPÇÕES METODOLÓGICAS
}

\section{GAMIFICATION APPLIED TO PRESERVICE PHYSICS TEACHERS IN THREE METHODOLOGICAL OPTIONS}

\author{
SILVA, André Coelho da ${ }^{1}$ \\ FORTUNATO, Ivan²
}

\begin{abstract}
RESUMO
Este artigo trata do conceito e da prática da gamificação na formação inicial docente, particularmente aplicada no curso de Licenciatura em Física. Metodologicamente, foi desenvolvido a partir da revisão de literatura e da análise de práticas desenvolvidas no referido curso de uma instituição federal de ensino, no interior do estado de São Paulo. Foram localizados poucos artigos publicados nas revistas de ensino de maior impacto no Brasil, sendo que nenhuma produção trata da particularidade da gamificação no ensino superior, direcionada para a formação docente de Física (ou Ciências). Apresentam-se três opções metodológicas, a saber, a gamificação para analogias, na promoção da memorização e revisão, e como possibilidade de experimentação de papéis. Ao final, reconhece-se o potencial da gamificação não apenas no engajamento das atividades de aprendizagem, mas seu papel na avaliação formativa de futuros professores. Como limites deste trabalho, apontam-se a investigação realizada em um centro de formação específico, tendo como indicação de novas pesquisas, outros centros de formação de professores de Física.
\end{abstract}

PalaVRas-Chave: Ensino de Física; gamificação; formação inicial de professores; metodologias de ensino.

\section{ABSTRACT}

This paper deals with the concept and practice of gamification in initial teacher education, particularly applied in preservice teaching course in physics. Methodologically, it was developed from the literature review, and from the analysis of practices developed in a course of a federal teaching institution in the interior of the state of São Paulo. Few articles were found in high impact teaching journals, none about gamification in higher education aimed at Physics (or Sciences) preservice teaching formation. Three methodological options are presented, namely gamification for analogies, promotion of memorization and revision, and the possibility of

\footnotetext{
1 Professor de Ensino Básico Técnico e Tecnológico do Instituto Federal de Educação, Ciência e Tecnologia de São Paulo (IFSP). Itapetininga, SP, Brasil. ORCID: https://orcid.org/0000-0003-13544034 e-mail: andco 8@yahoo.com.br

2 Professor do Instituto Federal de Educação, Ciência e Tecnologia de São Paulo (IFSP). Itapetininga, SP, Brasil. Professor do Programa de Pós-Graduação em Educação da Universidade Federal de São Carlos (UFSCAR). Sorocaba, SP, Brasil. ORCID: http://orcid.org/0000-0002-1870-7528 e-mail: ivanfrt@yahoo.com.br
} 
DOI: $10.12957 /$ e-mosaicos.2020.44414

experimenting with roles. In the end, the potential of gamification is recognized not only in the engagement of learning activities, but also in its role in the formative assessment of future teachers. As limits of this work we point out the research carried out in a specific training center, having as an indication of new research other training centers for physics teachers.

KEYWORDS: Physics teaching; gamification; initial teacher training; teaching methods.

\section{INTRODUÇÃO}

A adoção de atividades diversificadas em aulas de Física tem sido apontada como uma das formas de possibilitar o envolvimento de um maior número de estudantes nos processos de ensino e aprendizagem. De fato, a forma pela qual disciplinas como a Física costumam ser ensinadas, com foco na memorização de fórmulas e na resolução de exercícios mnemônicos, acaba privilegiando apenas uma parcela de alunos: aqueles que possuem certo domínio da Matemática (ZANOTELLO; ALMEIDA, 2007). Isso é ratificado pela recente publicação de Bonfim, Costa e Nascimento (2018), que constataram que o ensino ainda...

[...] tem sido realizado frequentemente mediante a apresentação de conceitos, de leis e fórmulas, de maneira desarticulada, distanciandose da realidade presenciada pelos alunos e professores e não só, mas também por isso, vazios de significado (Brasil, 2000). Consequentemente, o ensino de Física na Educação Básica vem se reduzindo a um trabalho extremamente frustrante de assimilação de fórmulas destinadas unicamente à resolução de problemas propostos por ocasião das provas. (BONFIM; COSTA; NASCIMENTO, 2018, p. 138)

Entre as inúmeras possibilidades de diversificação, destacamos a utilização de jogos, especialmente pela existência de diversos tipos, por sua dinamicidade e pela diversão envolvida - aspectos que, segundo Soares (2008), os tornam recursos sedutores para a prática docente. Ainda assim, conforme sinalizamos anteriormente (SILVA; FORTUNATO, 2016), parece haver escassez de trabalhos sobre a utilização de jogos no ensino de Física, seja no Ensino Básico ou no Ensino Superior. Nessa referida pesquisa, buscamos artigos sobre jogos em 546 edições de onze periódicos nacionais da área de ensino de Física/Ciências, não localizando um trabalho sequer no âmbito do ensino de Física.

Ao propor métodos de ensino por meio de jogos, Cunha (2012, p. 92) percebeu que "o interesse daquele que aprende passou a ser a força motora do processo de aprendizagem, e o professor, o gerador de situações estimuladoras para aprendizagem". Para essa autora, o ensino pelo lúdico estimula o interesse de quem aprende e possibilita, para o docente, uma condução mais sólida para a construção do conhecimento. Jann e Leite (2010) associam a ideia de lúdico à espontaneidade, flexibilidade e satisfação, compreendendo-o como necessário e fundamental para a vida humana. Segundo as autoras, 
DOI: $10.12957 /$ e-mosaicos.2020.44414

$\mathrm{Na}$ atividade lúdica, o que importa não é apenas o produto da atividade, o que dela resulta, mas a própria ação, o momento vivido. Possibilita a quem a vivencia momentos de encontro consigo e com o outro, momentos de fantasia e de realidade, de ressignificação e percepção, momentos de autoconhecimento e conhecimento do outro (JANN; LEITE, 2010, p. 284).

Embora possamos dizer que, devido a questões culturais, certos recursos e estratégias de ensino guardam maior coerência com aspectos lúdicos, consideramos que a ludicidade de determinada atividade didática depende, em maior medida, de como o recurso/estratégia é posto a funcionar durante o ato pedagógico. Os jogos, por exemplo, apesar de culturalmente estarem atrelados à ideia de diversão, podem ser utilizados na prática pedagógica de maneira extremamente enrijecida, levando os estudantes-jogadores ao tédio, decepção etc. Da mesma forma, a resolução de questionários com perguntas múltipla escolha - algo culturalmente atrelado à ideia de aborrecimento - dependendo das opções metodológicas do professor, pode funcionar como uma atividade lúdica, promovendo divertimento e gerando prazer na sua realização. Eis, então, que a ideia de gamificação (ora referida também como gamificação) parece atender aos propósitos de um ensino ancorado no lúdico. Retomando uma definição já apresentada, com base em Pelling (2011), podemos tomar a gamificação como "um processo que garante ao participante certas técnicas que implementam dinâmicas de jogo em diversas atividades, tais como o trabalho na empresa ou a educação na escola, a fim de realçar a interatividade, a fluidez, o engajamento e, principalmente, a motivação" (TEICHNER; FORTUNATO, 2015).

Assim, o objetivo deste trabalho é pensar questões associadas à gamificação no ensino de Física, revisando artigos sobre o tema e relatando experiências que temos desenvolvido junto a licenciandos de uma instituição pública federal. A expectativa é a de que a autorreflexão sobre essas experiências possa apontar possibilidades metodológicas para a adoção da gamificação no ensino de Física e fomentar o desenvolvimento de outros estudos sobre o assunto.

Para alcançar esse propósito, o artigo foi desenvolvido em quatro seções complementares: primeiro, apresentamos o conceito de gamificação. Em seguida, trazemos uma revisão sobre gamificação no ensino de Física em artigos publicados em periódicos da área de Ensino. Na sequência, investindo na relação entre a gamificação e a noção de mobilização, conforme proposta por Charlot (2000), relatamos e sistematizamos três opções metodológicas por meio das quais temos feito uso da gamificação em disciplinas de um curso de Licenciatura em Física. Depois de apresentadas as opções, realizamos uma análise com foco na gamificação e no seu potencial avaliativo. Ao final, esperamos que este trabalho contribua para que a gamificação seja mais explorada como uma estratégia didática na formação de professores de física, para que seu potencial se torne, cada vez mais, realidade concreta nas licenciaturas. 
DOI: 10.12957/e-mosaicos.2020.44414

\section{O QUE É A GAMIFICAÇÃO}

A definição mais sintética de jogo procura diferenciá-lo de uma brincadeira: um jogo é uma brincadeira organizada, ou seja, uma brincadeira com regras (PRENSKY, 2001). Akilli (2014, p. 274) caracteriza um jogo como uma atividade competitiva, criativa, agradável, delimitada por certas regras e que requer certas habilidades. Outras características dos jogos são: possuir um ou mais participantes, possuir um ou mais objetivos a serem alcançados pelos jogadores, envolver competição, envolver estratégia, conter um sistema de retroalimentação (feedback) que deixe claro o estado do jogo e possuir um jogador ou uma equipe vencedora (PRICE, 1990 apud AKILLI, 2014).

O termo gamificação é relativamente recente: seu primeiro uso documentado ocorreu em 2008 no escopo da indústria de mídia digital. Entretanto, somente a partir de 2010 o termo começou a se popularizar, abrangendo a área empresarial, de saúde, militar e educacional (DETERDING et al., 2011). Apesar de não haver uma definição consensual (ERENLI, 2013), em síntese, trata-se de usar a mecânica de jogos, elementos de jogos, em um contexto de "não-jogo" a fim de lhe oferecer sensações relacionadas ao jogar (DETERDING et al., 2011; ERENLI, 2013). Espera-se com isso, motivar os participantes a alcançarem determinados resultados comportamentais ou psicológicos (MATALLAOUI; HANNER; ZARNEKOW, 2017).

De acordo com Matallaoui, Hanner e Zarnekow (2017), a mecânica de jogos costumeiramente envolve elementos como: pontos (usados para recompensar os participantes); tabelas de classificação (para possibilitar aos participantes a comparação com os outros jogadores, estimulando-os a atingir as metas préestabelecidas); níveis (para indicar o progresso dos participantes); e tarefas-extra (para fornecer aos participantes objetivos adicionais). Segundo Kapp, Blair e Mesch (2014), os jogos normalmente contêm desafios, um mecanismo que possibilite tentativas múltiplas aos jogadores, algum tipo de sistema de recompensas, um objetivo claro que os jogadores trabalhem para alcançar e um objetivo final.

Nesse sentido, na gamificação são usados elementos como pontos, liberdade de falhar e proposição de desafios aos participantes. A intenção não é criar um jogo enquanto unidade independente, mas usar elementos de jogos para incentivar os participantes a se envolverem com o conteúdo e a progredirem em direção a um objetivo. Esta pode ser considerada a principal diferença entre um jogo e uma atividade gamificada. Nesta, é possível usar apenas um elemento de jogo, como atribuir um distintivo/insígnia a um participante que atingir determinado objetivo. Este elemento não torna a atividade em si um jogo, pois não se fazem presentes outros elementos (como níveis, desafios etc.) e tampouco há relação sistemática entre eles.

Kapp (2012) amplia o conceito de gamificação ao afirmar que, além de envolver a apropriação da mecânica de jogos, ela envolve também a apropriação da estética e do pensamento relativo a eles. Nessa direção, Kapp, Blair e Mesch (2014) apontam a existência de dois tipos de gamificação não mutuamente excludentes: a estrutural e a de conteúdo. A gamificação estrutural é a aplicação de elementos de jogos para 
impulsionar a motivação de um aluno, sem alterações no conteúdo. A estrutura em torno do conteúdo adquire semelhanças com um jogo, mas não o conteúdo em si. 0 foco principal desse tipo de gamificação é motivar os alunos e envolvê-los no processo de aprendizado por meio de recompensas. Os elementos mais comuns nesse tipo de gamificação são a inserção de pontos, insígnias e níveis. Já a gamificação de conteúdo é a aplicação de elementos de jogos para alterar o conteúdo, tornando-o mais semelhante a um jogo. Apresentar o conteúdo no contexto de uma história, ou de um desafio, está entre os métodos de gamificação de conteúdo.

A principal crítica à gamificação é a de que ela se tornou sinônimo de oferecimento de recompensas. De fato, a maioria das atividades gamificadas tem se baseado no oferecimento de pontos, prêmios, bônus e medalhas com a finalidade de atrair os participantes a buscá-las. Tratar-se-ia, assim, de estratégias voltadas somente à motivação extrínseca, isto é, a uma motivação artificial e pouco duradoura (KAPP; BLAIR; MESCH, 2014; NICHOLSON, 2015). Ainda assim, como salientado por Studart (2015), o "pensamento de jogo" (game thinking) está associado à motivação intrínseca, pois, em última instância, as pessoas não jogam um jogo apenas com a finalidade de ganhar pontos, mas sim com as finalidades de superar desafios, de atingir certo nível de competência e de socializar-se.

Kapp, Blair e Mesch (2014) acrescentam que, costumeiramente, ouvimos como justificativas para o uso de jogos, de simuladores e da gamificação em sala de aula, frases como "eles são legais e divertidos", "todo mundo gosta", "todo mundo brinca com jogos", "é fácil criá-los" e "eles possibilitam aprender sem esforço". Contrapondose a elas, os autores destacam que: o fato de serem divertidos, não implica em serem pertinentes/efetivos para a aprendizagem; nem todo mundo tem o costume de brincar com jogos, tampouco gosta de fazer isso; e que o uso didático de jogos requer o envolvimento dos participantes e a realização de atividades direcionadas a determinados objetivos - portanto, é necessário certo nível de esforço e determinação quando se participa de uma atividade gamificada. As justificativas plausíveis seriam as possibilidades de ampliar a interatividade, de aumentar o engajamento dos estudantes e de potencializar o pensamento e a reflexão. Nessa linha, segundo os autores, pesquisas têm sugerido que o nível de interatividade está diretamente relacionado à aprendizagem: quanto mais o estudante interagir com os colegas, o conteúdo e o professor, maior a probabilidade de ocorrer efetivo aprendizado.

Em síntese, podemos encarar a gamificação no ensino como uma estratégia que contém os seguintes elementos: regras; metas/missão e/ou conflitos/desafios; feedback; níveis de dificuldade e/ou pontos/placar e; principalmente, engajamento. Na seção seguinte, apresentamos um levantamento de artigos a respeito da prática da gamificação no ensino de Física.

\section{A GAMIFICAÇÃo No ENSINO de Física em PERIÓdicos da ÁREA de ENSINo}

Interessa-nos no âmbito deste trabalho, investigar se e como a gamificação tem sido utilizada no ensino de Física. Por conta disso, revisamos artigos em periódicos da área de Ensino de Física/Ciências que publicam majoritariamente em línguas 
DOI: $10.12957 /$ e-mosaicos.2020.44414

portuguesa e espanhola. Em específico, naqueles que, no quadriênio 2013-2016, foram classificados nos estratos A1, A2 e B1 da Área de Ensino do Qualis Periódicos avaliação realizada pela Coordenação de Aperfeiçoamento de Pessoal de Nível Superior (CAPES). Justificamos essa escolha por acreditarmos que revistas dessa natureza são as mais utilizadas pelos pesquisadores brasileiros da área de Ensino de Física, tanto para divulgar seus trabalhos, quanto para ter acesso aos trabalhos de seus pares. 0 quadro 01 , a seguir, explicita quais foram os 25 periódicos consultados:

Quadro 01. Periódicos revisados

\begin{tabular}{|c|c|}
\hline Nome do Periódico & Qualis Ensino \\
\hline Ciência \& Educação & \multirow{5}{*}{ A1 } \\
\hline Ensaio - Pesquisa em Educação em Ciências & \\
\hline Enseñanza de las Ciencias & \\
\hline Revista Brasileira de Ensino de Física & \\
\hline Revista Eureka sobre Enseñanza y Divulgación de las Ciencias & \\
\hline Acta Scientiae: Revista de Ensino de Ciências e Matemática & \multirow{13}{*}{ A2 } \\
\hline Alexandria: Revista de Educação em Ciência e Tecnologia & \\
\hline Amazônia - Revista de Educação em Ciências e Matemáticas & \\
\hline Areté - Revista Amazônica de Ensino de Ciências & \\
\hline Caderno Brasileiro de Ensino de Física & \\
\hline Investigações em Ensino de Ciências & \\
\hline Revista Brasileira de Ensino de Ciência e Tecnologia & \\
\hline Revista Brasileira de Pesquisa em Educação em Ciências & \\
\hline Revista de Educação, Ciências e Matemática & \\
\hline Revista de Ensino de Ciências e Matemática & \\
\hline Revista Electrónica de Enseñanza de las Ciencias & \\
\hline Revista Electrónica de Investigación en Educación en Ciencias & \\
\hline Vidya & \\
\hline Ciência \& Ensino & \multirow{7}{*}{ B1 } \\
\hline Ciência em Tela & \\
\hline Ensino de Ciências e Tecnologia em Revista & \\
\hline Experiências em Ensino de Ciências & \\
\hline Góndola: enseñanza e aprendizaje de las ciencias & \\
\hline Revista Ciências \& Ideias & \\
\hline Revista de Enseñanza de la Física & \\
\hline
\end{tabular}

As buscas foram feitas por meio da palavra "gamificação" e "gamificación" direcionada aos resumos dos artigos. Apenas três trabalhos foram encontrados: Costa e Verdeaux (2016), Silva e Sales (2017) e Aflitos et al. (2018). Por tratar exclusivamente da gamificação no Ensino Básico de Matemática, e não de Física ou Ciências, Aflitos et al. (2018) não foi considerado nesta revisão. Ainda assim, vale registrar que, por ter proporcionado engajamento e interação no processo de ensinar 
e aprender Matemática, os autores qualificaram como positiva a abordagem gamificada.

Tomando como referenciais a Teoria da Aprendizagem Significativa e noções associadas à gamificação, Costa e Verdeaux (2016) analisaram os resultados obtidos a partir da aplicação de uma sequência de ensino relacionada à modelagem matemática de fenômenos físicos a alunos do $9^{\circ}$ ano do Ensino Fundamental. Segundo os autores, jogos bem-sucedidos possuem: dificuldade progressiva; oferecem feedbacks rápidos aos participantes, dando-Ihes segurança nos acertos e possibilidade de correção dos erros - algo que muitas vezes não ocorre nos processos educacionais (os erros costumam custar caro aos estudantes: notas ruins, punições, reprovações etc.); envolvem diversão, desafio e recompensa; lidam de forma construtiva com os erros; e possuem estética e linguagem adequados. As tarefas e desafios propostos aos estudantes, bem como os conceitos de física trabalhados, estavam no contexto de uma narrativa sobre atrasos e brigas de namorados.

As análises dos resultados obtidos foram pautadas num pré-teste, num pósteste e num questionário de opinião. Havia um grupo controle e um grupo experimental - com este foi desenvolvida em oito encontros a sequência didática gamificada e com aquele, mantiveram-se as aulas habituais sobre o mesmo tema. Em termos de conhecimentos prévios, os dois grupos se mostraram razoavelmente equivalentes, panorama que não se manteve após a intervenção. O grupo controle só superou o grupo experimental em uma das sete questões, indicando, segundo os autores, que os estudantes do grupo experimental assimilaram mais o conteúdo em comparação aos do grupo controle. Em específico, aqueles demonstraram maior autonomia de pensamento - o que estaria associado às tarefas de casa que requeriam a realização de missões sem a ajuda do professor - e maior habilidade para efetuar generalizações matemáticas.

Quanto ao questionário de opinião respondido pelos estudantes do grupo experimental, seus resultados evidenciaram que, entre outras coisas: a presença de um enredo/história fomentou a manutenção da motivação e da atenção; a formação de grupos foi apontada como algo positivo; o oferecimento de recompensas na forma de estrelas foi fator de motivação para a maioria; houve predileção pela metodologia utilizada na sequência didática quando comparada à metodologia tradicional de ensino; os estudantes avaliaram ter compreendido o conteúdo. Concluindo, Costa e Verdeaux (2016) apontam que a gamificação pode funcionar de maneira produtiva junto ao engajamento dos estudantes, possibilitando situações interessantes para a aprendizagem.

Silva e Sales (2017) analisaram resultados obtidos a partir de um curso gamificado sobre Óptica, realizado por quinze estudantes de um curso técnico integrado em eletrotécnica. Após revisarem a literatura da área, os autores sinalizam a escassez de trabalhos sobre o uso da gamificação em aulas de Física. Por outro lado, salientam que, apesar de se tratar de um termo relativamente novo, práticas associadas à gamificação já seriam utilizadas e fariam parte do sistema escolar há muito tempo. Recompensar os estudantes com estrelinhas, organizar as turmas em 
séries, requisitar que os estudantes alcancem certa quantidade mínima de pontos para passarem para a série seguinte, exigir que estudantes que não alcançam os objetivos repitam o processo e oferecer feedback aos estudantes após as avaliações, estariam entre as práticas afeitas à gamificação e que já fazem parte do contexto escolar.

A experiência desenvolvida em sala de aula fez uso, entre outros elementos de jogos, de desafios a serem cumpridos pelos estudantes individualmente e em grupos e de quizzes (usando a ferramenta Kahoot!) em que se oferece aos estudantes feedback imediato de seus acertos e erros. Após a finalização das atividades os estudantes responderam a um questionário de opinião composto por doze questões estruturadas com base na escala Likert. A análise das respostas obtidas evidenciou que a maioria dos participantes julgou que a gamificação das atividades favoreceu a aprendizagem, especialmente pela presença de desafios que os estimulavam.

Em síntese, os trabalhos revisados evidenciam que o conceito de gamificação é relativamente novo e que há carência de publicações sobre o assunto - sinalizando se tratar de um campo a ser explorado. Além disso, os autores dos trabalhos relatam positivamente as experiências desenvolvidas, acreditando na gamificação como uma estratégia bastante eficaz na promoção da aprendizagem. Por fim, há que se registrar que os três artigos descreveram e analisaram situações/ferramentas gamificadas aplicadas na educação básica (final do ensino fundamental e curso técnico integrado, respectivamente), abrindo espaço para que sua implementação seja realizada e investigada com estudantes de licenciatura, focando na formação inicial docente.

\section{A gaMificAÇÃo NA FORMAÇÃo INICIAL de PROFESSORES DE FísicA: RELATANDO EXPERIÊNCIAS}

Investindo na relação entre a gamificação e a noção de mobilização conforme proposta por Charlot (2000), relatamos e sistematizamos três formas diferentes por meio das quais temos feito uso da gamificação em disciplinas de um curso de Licenciatura em Física. Para o autor:

O conceito de mobilização implica a ideia de movimento. Mobilizar é pôr em movimento; mobilizar-se é pôr-se em movimento. Para insistir nessa dinâmica interna é que utilizamos o termo de "mobilização", de preferência ao de "motivação". A mobilização implica mobilizar-se ("de dentro"), enquanto que a motivação enfatiza o fato de que se é motivado por alguém ou por algo ("de fora"). É verdade que, no fim da análise, esses conceitos convergem: poder-se-ia dizer que eu me mobilizo para alcançar um objetivo que me motiva e que sou motivado por algo que pode mobilizar-me. [...] Mobilizar-se, porém, é também engajar-se em uma atividade originada por móbiles, porque existem "boas razões" para fazê-lo. Interessarão, então, os móbiles da mobilização, o que produz a movimentação, a entrada em atividade. [...] A criança mobiliza-se, em uma atividade, quando investe nela, quando faz uso de si mesma como de um recurso, quando é posta em 
DOI: $10.12957 /$ e-mosaicos.2020.44414

movimento por móbeis que remetem a um desejo, um sentido, um valor. (CHARLOT, 2000, p. 55)

Ainda que muitos autores, tais como Lima e Soares (2010), Lima (2011), Freitas, Furlan e Kunze (2011), defendam o papel motivacional dos jogos, é potencialmente mais educativo tomá-los como móbiles da ação, conforme proposto por Charlot (2000). Pensar um jogo ou um elemento de jogo (pontos, níveis etc.) como móbile implica, portanto, considerá-lo como um atrativo para a mobilização dos estudantes, como uma forma de engajá-los no processo de aprendizagem: a gamificação de uma atividade pode funcionar como um móbile da aprendizagem.

Tendo em vista essa consideração e as discussões efetuadas nas seções anteriores com base na literatura consultada, caracterizamos três possibilidades para uso didático da gamificação na formação de professores: (1.) gamificação das analogias; (2.) gamificação para promover memorização e revisão; e (3.) gamificação como possibilidade de experimentação de papeis.

Efetivamente, essas diferentes opções metodológicas refletem o principal objetivo/finalidade com o qual certos elementos de jogos são didaticamente utilizados. É oportuno dizer que ao invés de pensarmos tais possibilidades como algo estanque (categorias mutuamente excludentes), acreditamos na fluidez dessas opções, isto é, na inexistência de limites rígidos entre elas. Nesse sentido, uma atividade gamificada pode ser utilizada simultaneamente com múltiplos objetivos, ou seja, com várias finalidades didáticas. Além disso, certamente as opções caracterizadas estão distantes de esgotarem as possibilidades e de forma alguma esse é o nosso objetivo. A proposta é estudar/propor meios de sistematização que favoreçam o pensar acerca da gamificação como opção didática.

\section{OPÇÃo METODOLÓGICA 01: A GAMIFICAÇÃO DAS ANALOGIAS}

Embora sejam apontadas algumas limitações da utilização de recursos analógicos no ensino de Física/Ciências - por exemplo: a ideia de que a analogia pode ser interpretada como o conceito em estudo em si, ou a possibilidade de apenas seus detalhes mais evidentes e apelativos serem identificados pelos estudantes (Duarte, 2005) - sua utilização pedagógica tem sido defendida por diversos autores. Silva e Terrazzan (2011), por exemplo, afirmam que, ao compararem dois conceitos que detêm certa semelhança, as analogias permitem explicar algo desconhecido, proporcionando sua compreensão. Assim, toda analogia é constituída pelo análogo (o conhecimento familiar), o alvo (o conhecimento desconhecido) e as relações analógicas (relações que estabelecem as semelhanças e diferenças entre análogo e alvo).

As analogias costumam ser empregadas didaticamente, especialmente quando os conceitos/noções estudados não se relacionam diretamente a nossas percepções. Quando falamos em sólidos, por exemplo, somos capazes de encontrar por meio de 
nossas percepções exemplos de objetos sólidos que estão ao nosso redor. Já se falamos em elétrons, o panorama não é o mesmo: não somos capazes de encontrar por meio de nossas percepções exemplos de elétrons. Na própria história da ciência podemos enumerar situações em que o entendimento de fenômenos não observáveis mediante o uso dos sentidos humanos se deu por meio de processos de pensamento que envolveram o recurso analógico (Silva e Terrazzan, 2011). Portanto, ao afirmarmos que uma das opções metodológicas para o uso didático da gamificação é incorporá-la às analogias, estamos salientando a possibilidade de que determinados elementos de jogos mobilizem os estudantes para que estabeleçam relações pertinentes entre $\mathrm{o}$ alvo e $\mathrm{o}$ análogo.

Aspectos do funcionamento da radiografia e da tomografia computadorizada são temas que temos trabalhado em uma das disciplinas de um curso de Licenciatura em Física. Para introduzir a questão de como os raios $X$ são utilizados para a formação das imagens resultantes desses exames, utilizamo-nos de uma atividade gamificada que visa estabelecer uma analogia entre esse processo e o processo de formação de sombras. Ela prescinde dos seguintes materiais: uma luminária com uma lâmpada potente; uma tela de projeção; e objetos relativamente pequenos (moeda, maçã, anel, armação de óculos etc.). Desempenhamos o papel de mediadores, projetando as sombras uma de cada vez e com nível de dificuldade crescente, questionando os estudantes (individualmente ou organizados em grupos) de que objeto é a sombra que estão vendo (da posição onde eles se encontram são capazes de ver apenas a sombra do objeto e não o objeto em si), registrando a pontuação dos estudantes/grupos na lousa (cada acerto equivale a um ponto) e conduzindo o feedback: após cada rodada, o professor e os estudantes comentam quais as características possibilitavam a identificação da sombra.

A relação analógica estabelecida visa a proporcionar o entendimento de que a imagem radiográfica também é algo como uma sombra, em que as regiões mais claras e escuras representam diferentes níveis de absorção de radiação. A diferença reside no tipo de radiação utilizada: raios $\mathrm{X}$ e não luz visível como no caso das sombras "habituais".

Na oitava e última rodada do jogo, produzimos uma sombra de dois objetos sobrepostos, de forma a impossibilitar a identificação de que a sombra se refere a dois objetos e não a apenas um como nas sete rodadas anteriores. $O$ objetivo é abordar as limitações da radiografia enquanto técnica para obtenção de imagens médicas e como a tomografia computadorizada por raios $\mathrm{X}$ atua para suprir tais limitações. A relação analógica está associada ao fato de que em muitas regiões do corpo humano há sobreposição de estruturas, o que pode dificultar ou impossibilitar análises médicas por meio de radiografias. Em resumo, tal problema é consequência da produção de uma imagem em duas dimensões (2D) a partir de algo que possui três dimensões (3D), ou seja, o corpo humano e suas estruturas. A impossibilidade de identificar que a última sombra era relativa à sobreposição de dois objetos é utilizada como mote para a introdução de como funciona uma tomografia computadorizada. Embora também utilizem como radiação os raios $X$, os aparelhos de tomografia 
DOI: $10.12957 /$ e-mosaicos.2020.44414

computadorizada possibilitam superar essa limitação ao adotarem um mecanismo que gira ao redor do paciente, sendo capaz de produzir imagens de diferentes seções transversais do corpo.

Por fim, vale dizer que vence a disputa o estudante/grupo que acumular mais pontos ao final das oito rodadas. Dessa forma, em conjunto com os demais aspectos, a competição envolvida nessa atividade tem como finalidade funcionar como móbile da aprendizagem.

\section{OPÇÃo METODOLÓGICA 02: GAMIFICAÇÃO PARA PROMOVER MEMORIZAÇÃO E REVISÃo}

O incentivo à memorização muitas vezes é alvo de críticas por parte de educadores e pesquisadores da área de ensino. Apesar disso, acreditamos que ela desempenha papel importante nos processos de aprendizagem. Especificamente no caso da Física, muitas críticas têm sido dirigidas ao ensino que é guiado pela memorização de fórmulas e definições para posterior aplicação em exercícios, cujas resoluções envolvam procedimentos repetitivos (CARVALHO JR., 2002; ZANETIC, 2005). Em tal abordagem, professor e aluno são vistos, respectivamente, como transmissor e receptor de informações, sendo que aprender se torna sinônimo de adquiri-las e, portanto, quem aprendeu sabe repeti-las sozinho.

Estamos de acordo com as críticas dirigidas a essa abordagem, especialmente porque considera a memorização como o único fim possível e desejável para os processos de aprendizagem. A aprendizagem envolve não apenas o "lembrar", mas também o "entender" (MAYER, 2009). Enquanto "lembrar" implica reproduzir e reconhecer algum conteúdo, "entender" envolve a construção de um modelo mental coerente acerca do conteúdo estudado. Por exemplo: um aluno de Física pode ser capaz de reproduzir os processos de resolução de exercícios trabalhados em sala de aula mesmo sem entendê-los. Similarmente, ele pode ter entendido tais processos, mesmo não sendo capaz de reproduzi-los sozinho.

Pensar atividades gamificadas que promovam a memorização parece fazer bastante sentido ao lembrarmos que, em geral, os jogos envolvem a realização e a repetição de determinadas rotinas. No "Dominó", por exemplo, o jogador sempre procura por peças que possam ser encaixadas na sequência de peças que estão sobre a mesa. No "Jogo da Memória", o jogador sempre vira duas cartas procurando formar o par de cartas iguais. Dessa forma, acreditamos que é possível planejar atividades gamificadas de maneira a aproveitar didaticamente a repetição dessas rotinas.

Por outro lado, conforme já apontamos, a aprendizagem não se resume à memorização, tampouco se resume a uma questão de tudo ou nada, ou seja, alguém aprendeu ou não aprendeu, sabe ou não sabe. Para nós, a aprendizagem é um processo e, como tal, novos contatos com um mesmo conteúdo podem potencializar e qualificar a aprendizagem. Isso pode ocorrer, especialmente, se tais contatos são estabelecidos por meio de atividades diversificadas e diferentes perspectivas. Potencializar e qualificar, porque novos olhares nunca são idênticos aos anteriores (nossas experiências nos tornam diferentes em relação ao que éramos em 
oportunidades passadas) e, logo, oferecem-nos a possibilidade de rever, cristalizar ou agregar significados a nossas concepções.

$O$ ato de fazer recapitulações é um dos traços didáticos de um discurso, isto é, um recurso que visa a tornar um texto/fala mais acessível, mais fácil ao entendimento (FERREIRA; QUEIROZ, 2012). O uso de atividades gamificadas como oportunidade de revisão vai ao encontro dessas considerações ao possibilitar aos estudantes novos e diversificados contatos com assuntos já trabalhados pelo professor. Mesmo sendo válido afirmar que as revisões podem ser feitas utilizando diferentes metodologias, há que se considerar que o caráter lúdico, interativo e social associado aos jogos pode favorecer o uso de um ou mais de seus elementos para tal finalidade.

No âmbito da Física Moderna e Contemporânea, temos utilizado o jogo "Dominó Radioativo" como promotor da memorização dos diferentes processos de decaimento radioativo. Há três séries radioativas naturais, isto é, três cadeias de decaimento seguidas por elementos radioativos. Quando um elemento radioativo decai ele se transforma em outro elemento químico que também é radioativo, o qual ao decair também irá se transformar em outro elemento químico que também é radioativo e assim por diante, até que após uma longa e demorada sequência, produz-se um elemento estável (não radioativo). O Urânio-238, por exemplo, após decair se transforma em Tório-234, que, por sua vez, ao decair se transforma em Protactínio234, que decairá dando origem ao Urânio-234 etc. Os decaimentos associados a essas transformações de elementos radioativos em outros são os chamados decaimentos alfa e beta. Enquanto no decaimento alfa o número de massa (soma do número de prótons com o número de nêutrons) do elemento químico diminui quatro unidades, no decaimento beta tal número não é alterado. Embora tais decaimentos também afetem o número atômico dos elementos (número de prótons), cremos que a compreensão de nosso relato sobre o mecanismo do jogo utilizado não necessita do entendimento de tal processo. No exemplo anterior, portanto, o Urânio-238 (onde 238 é o número de massa do elemento) sofreu um decaimento alfa, pois se transformou em um elemento com número de massa quatro unidades menor (o Tório-234). Já o Tório-234 sofreu um decaimento beta, pois se transformou em um elemento com mesmo número de massa (Protactínio-234).

O "Dominó Radioativo" é composto por peças que indicam concomitantemente o elemento químico e o tipo de decaimento que ele sofre. Cada estudante/grupo recebe determinado número de peças (igual para todos). Caso sobrem peças, elas ficam em um monte, disponíveis para serem "compradas". O professor indica qual é o elemento "pai" da série radioativa (o primeiro elemento da série - o Urânio-238, por exemplo) e o participante que a detém inicia a atividade. Em seguida, sorteia-se a ordem de participação entre os demais participantes. Em cada peça consta o tipo de decaimento que o elemento sofre (alfa ou beta). Sendo assim, é possível determinar qual peça dará continuidade à sequência. Se o participante tiver a peça que representa o elemento seguinte do dominó, ele o encaixa na série e passa a vez. Se não tiver, compra outra peça do monte (caso ele exista) e passa a vez. Após cada peça encaixada na série, o professor reforça o que ocorre com os números de massa e atômico dos 
elementos radioativos quando decaem. Vence a partida (pontuação máxima) o primeiro a ficar sem peças, mas ela continua até a série ser completada - os outros participantes ganham pontuações decrescentes conforme a ordem em que ficam sem peças. Os pontos acumulados por cada participante/equipe em cada partida vão sendo registrados na lousa. A atividade é vencida por aquele que acumular mais pontos considerando a soma de pontos nas três partidas (cada uma corresponde a uma das três séries radioativas).

Temos notado que a utilização desse jogo favorece a memorização das diferenças entre os decaimentos alfa e beta - a influência que cada um deles tem sobre o número de massa e o número atômico dos elementos radioativos - bem como a memorização dos nomes e símbolos dos elementos químicos. Vale mencionar também que o jogo tem sido utilizado pelos licenciandos em práticas desenvolvidas com estudantes do ensino médio durante atividades de estágio ou no âmbito de programas como o PIBID (Programa Institucional de Bolsas de Iniciação à Docência) e a Residência Pedagógica.

Ainda no contexto de uma disciplina em que abordamos elementos históricos e conceituais de tópicos de Física Moderna e Contemporânea, nas últimas aulas do semestre letivo temos utilizado um jogo no formato de quiz (um jogo de questionário) como oportunidade de revisão dos assuntos discutidos ao longo do semestre. Cada grupo de alunos recebe "plaquinhas" com letras de "a" a "e", representando as alternativas das questões que projetamos na tela. Lemos cada questão e suas respectivas alternativas em voz alta para a turma, dando $40 \mathrm{~s}$ para que os estudantes conversem dentro de seus grupos a fim de chegarem à conclusão de qual alternativa está correta (apenas uma por questão). Após o término do tempo, pedimos para que cada grupo levante a "plaquinha" que representa a alternativa correta segundo a opinião dos integrantes. Antes de apresentar a alternativa correta, comentamos cada uma das outras quatro alternativas, explicando porque elas estão erradas. Justificamos também porque uma delas está correta. Os grupos que acertaram acumulam um ponto. Após o término das 25 questões, o grupo que tiver mais pontos é declarado o vencedor.

A gamificação dessa atividade procura mobilizar os estudantes para a prática de uma revisão, fortalecendo ou a incorporando significados às concepções construídas ao longo da disciplina. Vale ressaltar que a resolução das questões não envolve a realização de cálculos. São questões ou de caráter conceitual, ou que remetem a elementos históricos da Física Moderna e Contemporânea discutidos em sala de aula. Antes do início da atividade deixamos combinado que o desempenho dos grupos poderá valer até um ponto extra na média dos estudantes que o compõe. A conversão do número de questões acertadas para ponto extra é feita por meio de porcentagem. Acertar 25 questões equivale a um ponto na média, acertar 20 questões equivale a 0,8 ponto na média etc. 
DOI: $10.12957 /$ e-mosaicos.2020.44414

\section{OPÇÃo METODOLÓGICA 03: GAMIFICAÇÃO COMO POSSIBILIDADE DE EXPERIMENTAÇÃO DE PAPEIS}

O desempenho e a interpretação de papeis sociais estão entre as características de determinados jogos que podem ser aproveitadas como recurso pedagógico para a formação de docentes. É comum nos cursos de licenciatura, que os estudantes treinem o papel de professor ao apresentarem seminários ou simularem ser o professor de seus colegas. Essa prática trivial pode ser potencializada, se compreendido que dramatizar um papel "tem por finalidade levar o indivíduo a uma expressão espontânea e criativa, que possibilite a recriação dos papéis rigidamente desempenhados na situação real, análoga à da representação" (NAFFAH NETO, 1979, p. 23). Dessa forma, a proposta de apresentar seminários ou "dar aulas" na licenciatura, para licenciandos, pode tornar-se algo muito mais profundo do que uma simples atividade que compõe o rol de coisas a fazer em determinada disciplina.

O futuro professor pode, durante o período de sua formação inicial, ser levado a experimentar situações do cotidiano docente por meio de atividades gamificadas que o levem a vivenciar a realidade. Para tanto, é preciso sempre registrar e refletir sobre o cotidiano vivido na escola, pois é do cotidiano que são colhidas as vivências que se tornam potenciais conjunturas para serem oferecidas em atividades gamificadas de experimentação de papeis.

Nas disciplinas de Didática e Prática Docente, atividades gamificadas de dramatização como possibilidade de experimentação têm sido propostas como móbiles do trabalho didático, mas, principalmente, para elucidar aspectos cotidianos do ambiente escolar, especialmente aqueles que sobrepujam qualquer planejamento e demandam criatividade para solução imediata. Exemplo dessas atividades é a "mudança repentina de sala", que começa com uma investigação de memória autobiográfica, tendo como divisa a busca por uma aula que o licenciando recorda ter sido uma boa experiência. Pede-se, então, que cada um registre, em uma folha de papel qual era a disciplina (História, Geografia, Física, Matemática...) e o tema da aula (independência do Brasil, clima tropical, equação de Torricceli, diagrama de EulerVenn...). Apenas isso, sem identificação alguma. Feito isso, as folhas são dobradas, embaralhadas e sorteadas entre os estudantes. Na sequência, a situação imaginada é criada: você precisa, daqui meia hora, substituir o professor da disciplina $X$, e conduzir uma aula sobre o tema $Y$ para uma turma do ensino fundamental ou médio $-X$ e $Y$ estão na folha que foi sorteada.

Esse tipo de atividade exagera algumas situações inesperadas que acontecem no dia a dia escolar, mas que não são, em absoluto, fantasiosas. As dificuldades que os licenciandos têm de preparar uma aula em tão pouco tempo são exercícios importantes, pois evidenciam um dos grandes desafios da profissão: a dinâmica do cotidiano. Trata-se também de uma atividade que estressa alguns limitantes mais comuns, como a falta de material adequado para a preparação e a condução da aula.

Embora não se contem pontos, pode se torná-la mais fácil ou mais difícil, na medida em que se alteram seus elementos principais, como o tempo de preparação, 
que pode ser reduzido até 15 minutos, por exemplo, (simulando uma troca repentina de turma, ou a substituição de um colega professor que não comparece para sua aula regular). Da mesma forma, a dificuldade pode ser ajustada no tempo da aula simulada, que pode ser uma apresentação breve de 5 a 10 minutos, como pode ser desenvolvida no tempo habitual das escolas, ou seja, dois períodos de 50 minutos consecutivos, totalizando uma hora e quarenta minutos. Pode-se, ainda, restringir o material de pesquisa (evitar a biblioteca e o acesso à internet, não permitir o uso de computador pessoal para elaboração de roteiro de aula ou slides), bem como o material disponível para aula, reduzindo-o a giz e lousa. Outro elemento que pode facilitar ou dificultar a atividade é sua realização em grupos, duplas ou de forma individual, sem qualquer possibilidade de interação ou colaboração entre os pares.

Como forma de retroalimentação (feedback) do desempenho individual ou coletivo, logo após o término da aula simulada ocorre um momento de comentários sobre os aspectos positivos e negativos de todo o trabalho, desde o planejamento, passando pelo desempenho didático, manejo dos recursos, até o encerramento da aula. Quem participa dessa etapa, além do docente, são os colegas em formação, dispostos a colaborar com a formação de seus companheiros de turma.

As experiências com essa atividade gamificada, aplicada ao longo dos últimos anos na formação docente, têm se mostrado positivas no quesito engajamento: há uma participação coletiva e intensa, desde o momento de registrar uma aula aleatória no papel, até a hora de contribuir com feedbacks positivos e negativos.

\section{ANÁLISE DAS OPÇÕES METODOLÓGICAS DE GAMIFICAÇÃO}

Ao apresentar as três opções metodológicas, exemplificando-as, pudemos perceber os principais elementos que as caracterizam como atividades gamificadas. Em todas elas há regras essenciais a serem seguidas, claramente descritas e apresentadas aos estudantes antes do seu início. Cada atividade, à sua maneira, tem suas metas/missão, bem como um ou mais desafios e/ou conflitos a serem superados - seja descobrir os objetos pela sua sombra, identificar as peças que podem ser encaixadas na séria radioativa, determinar a resposta correta em cada quiz, ou preparar uma aula de forma súbita. Todas as atividades, ainda, são elaboradas de forma a fornecer feedback praticamente instantaneamente após cada rodada, seja um feedback individual, dado apenas pelo docente responsável, ou coletivo, com a colaboração de todos os colegas, indicando aspectos positivos ou a serem melhorados, ou apenas informando a pontuação de cada jogador ou equipe. Outro elemento da gamificação presente nas opções metodológicas são os níveis de dificuldade e/ou placar de pontos. Na atividade da analogia, por exemplo, começa-se com sombras de objetos facilmente discerníveis, evoluindo para sombras de objetos mais peculiares e chegando a uma sombra de dois objetos sobrepostos. Por fim, e talvez mais importante, todas possibilitam o engajamento, evidenciado pela participação coletiva em todas as etapas da atividade, inclusive no momento de feedback aos colegas. 
DOI: $10.12957 /$ e-mosaicos.2020.44414

Nota-se, portanto, que as três opções metodológicas caracterizadas procuram favorecer o caráter lúdico associado à gamificação, sem descuidar daquilo que nos parece a essência de qualquer atividade de ensino e aprendizagem: seu objetivo pedagógico, o qual implica, além dos aspectos de ensino, elementos de avaliação da aprendizagem (e do próprio processo de ensinar).

Grosso modo, podemos distinguir dois tipos de avaliação: as formativas e as somativas (FERREIRA; CARVALHO, 2002). Avaliações formativas são realizadas durante o processo pedagógico visando à obtenção de informações que sejam úteis para melhorar o entendimento do aluno a respeito de determinado assunto. Avaliações somativas são realizadas ao final do processo pedagógico objetivando medir e classificar os alunos de acordo com o que supostamente aprenderam ou não. Essa última concepção remete ao paradigma educacional conhecido como tecnicista, cujas bases estão no entendimento de que a escola só pode melhorar a partir do treino adequado dos professores e do bom gerenciamento da instituição de ensino (Freitas, 1997). Entretanto, especialmente por envolver seres humanos com distintas histórias de vida, concordamos com o autor, ao defender que a educação é algo mais complexo e não uma questão puramente técnica.

Infelizmente, ainda parece prevalecer em nossas instituições de ensino a ideia "tradicional" de avaliação (coerente com a concepção de avaliação somativa). No ensino de Física, as chamadas "provas" costumam privilegiar o conhecimento lógicomatemático dos estudantes, não levando em consideração outros conhecimentos e tampouco os diferentes estilos de aprendizagem. Costumam resultar também na fixação de rótulos aos alunos: os bons e os ruins, gerando sentimentos negativos perante as avaliações e as instituições de ensino como um todo.

Dentro desse contexto, jogos ou atividades gamificadas em que apenas o resultado final é considerado ou em que as ideias de vencedor e perdedor são exaltadas em demasia encontram consonância com a concepção de avaliação somativa. Por outro lado, as características associadas aos jogos evidenciam também divergências entre o uso didático de um ou mais de seus elementos e as avaliações somativas, especialmente no que se refere ao caráter lúdico dos jogos versus o caráter punitivo das "provas". Logo, ao falarmos em jogos como instrumentos de avaliação, num primeiro momento, abrem-se duas possibilidades: jogos como instrumento de avaliação somativa e jogos como instrumento de avaliação formativa. Particularmente, por não concordarmos com os pressupostos que sustentam a ideia de avaliação somativa e com a exaltação da competição no âmbito pedagógico, defendemos a outra possibilidade, isto é, os jogos como instrumentos de avaliação formativa.

No que diz respeito à utilização de atividades gamificadas como instrumento de avaliação, é válido afirmar que duas das atividades relatadas possuem características de avaliação formativa. O "Dominó Radioativo", além de favorecer a memorização, possibilita avaliar o entendimento dos licenciandos acerca dos tipos de decaimento radioativo. Um estudante que não está conseguindo participar corretamente da atividade provavelmente não compreendeu os assuntos envolvidos. A obtenção desse diagnóstico pode ser útil para o professor (que poderá trabalhar com o intuito de 
auxiliar os sujeitos a superarem as dificuldades de compreensão) e para os próprios estudantes (que poderão ter acesso a informações que proporcionem a realização de autoavaliações). O mesmo raciocínio vale para o caso do quiz: ao estabelecermos o desempenho no jogo como estando relacionado a uma pontuação extra visamos minimizar a imagem de que se trata de uma avaliação somativa e favorecer a imagem de que se trata de uma atividade de caráter lúdico - sem negligenciar sua principal finalidade: funcionar como revisão. Já no caso do jogo da aula simulada, fica patente que o propósito da sua avaliação, ao final, é qualitativo, tocando em aspectos relacionados à habilidade didática e à condução pedagógica de uma aula.

\section{CONSIDERAÇõES FINAIS}

Como esperamos ter evidenciado em nossos relatos sobre as opções metodológicas por meio das quais temos feito uso da gamificação, não se trata de opções estanques, mas de opções que muitas vezes acabam se sobrepondo e funcionando de maneira conjunta. Nesse sentido, o esforço teórico empreendido neste trabalho visa a contribuir junto à realização de outros estudos que se proponham a pensar questões associadas à gamificação, especialmente na formação inicial de professores de Física.

De fato, os resultados que obtivemos em nossa revisão de literatura sinalizam a escassez de trabalhos sobre a gamificação no ensino de Física, sobretudo no contexto de cursos de Licenciatura. Dessa forma, considerando os potenciais da gamificação discutidos ao longo deste trabalho, trata-se de uma lacuna cujo preenchimento nos parece pertinente, ainda mais quando se assume a relevância de que os futuros professores vivenciem durante suas formações experiências que possam servir como exemplos a serem relidos e reestruturados quando estiverem em sala de aula. Em outras palavras: se os licenciandos não experienciarem atividades gamificadas para que possam refletir sobre suas potencialidades e limitações num contexto que alie teoria e prática, parece-nos pouco produtivo simplesmente sugerir a eles algo como: "quando estiverem em sala de aula, é importante que vocês planejem e executem atividades gamificadas".

As opções metodológicas sistematizadas e os relatos efetuados também apontam possíveis caminhos para a desconstrução da visão costumeiramente aceita para o ato de avaliar no âmbito das práticas de ensino e aprendizagem. 0 caráter lúdico, a presença de feedbacks e o engajamento alcançado com as atividades gamificadas sinalizam para outra direção, valorizando a avaliação como parte do processo e com finalidade voltada para a potencialização da aprendizagem - e não como o fim, como o juízo final de uma prática pedagógica.

Assim, seja gamificando analogias, memorização e revisão e/ou o exercício da docência, temos buscado meios de tornar mais dinâmica a formação inicial de professores de física. Ao desenvolver atividades gamificadas, esperamos alcançar o engajamento para docência, inclusive daqueles que frequentam o curso de licenciatura, mas não almejam tornarem-se professores no futuro. Pelo lúdico, temos como propósito revelar que ensinar pode também ser algo não apenas voltado para 
DOI: $10.12957 /$ e-mosaicos.2020.44414

a formação racional, mas também sensível. Afinal, a mobilização do emocional é algo intrínseco ao jogo, pois, por mais que se precise de habilidades cognitivas para jogálo, é preciso atenção, comunicação, autoconfiança, paciência, persistência etc.

Finalizando, gostaríamos de salientar a importância de não tornar o uso de jogos ou da gamificação como uma forma de incentivar as ideias de vencedor e perdedor. Nesse sentido, embora muitas vezes o sentimento de estar competindo possa favorecer a mobilização para aprender, em excesso ele pode gerar sentimentos negativos em relação aos outros e a si mesmo (intolerância e decepção acentuada, por exemplo). Ao invés da ideia de competição, parece-nos mais interessante assentar o uso de atividades gamificadas sobre as ideias de colaboração e cooperação, afinal, nos processos de ensino a dicotomia vencedor/perdedor não faz sentido. Se nos jogos só existem vencedores porque há perdedores, nas escolas e universidades deveria ser diferente: só devia haver vencedores, ou seja, estudantes que conseguissem atingir os objetivos de aprendizagem propostos, ainda que entre si eles o fizessem em tempos e de maneiras diferentes.

Como limites deste trabalho, reconhecemos o caráter restrito de nossas análises, realizadas apenas no contexto de práticas desenvolvidas num único centro de formação de professores de física. Não obstante, a quase ausência de artigos sobre o tema da gamificação no ensino de física e a inexistência de pesquisas publicadas voltadas especificamente à aplicação da gamificação na formação inicial de professores dessa disciplina nos coloca diante de um campo exploratório, no qual a bibliografia básica e os resultados iniciais e parciais aqui identificados o apresentam como potencial a ser investigado com mais profundidade e envergadura. Quem sabe, não estamos diante de uma estratégia didática fundamental para uma formação docente de qualidade?

\section{REFERÊNCIAS}

AFLITOS, O. L. et al. Khan Academy - uma ferramenta gamificada em ensino e aprendizagem de matemática. Areté - Revista Amazônica de Ensino de Ciências, v. 11, n. 23, p. 1-12, 2018.

AKILLI, G. K. Games and Simulations: a new approach in education? In: J. Bishop (org.). Gamification for human factors integration: social, education, and psychological. Hershey: Information Science Reference, 2014. p. 272-289.

BONFIM, D. D. S., COSTA, P. C. F.; NASCIMENTO, W. J. A abordagem dos três momentos pedagógicos no estudo de velocidade escalar média. Experiências em Ensino de Ciências, Cuiabá, v. 13, n. 1, p. 187-197, 2018.

CARVALHO Jr., G. D. As concepções de ensino de Física e a construção da cidadania. Caderno Catarinense de Ensino de Física, v. 19, n. 1, p. 53-66, 2002. 
DOI: $10.12957 /$ e-mosaicos.2020.44414

CHARLOT, B. Da relação com o saber: elementos para uma teoria. Porto Alegre: Artes Médicas Sul, 2000.

COSTA, T. M.; VERDEAUX, M. F. S. Gamificação de materiais didáticos: uma proposta para a aprendizagem significativa da modelagem de problemas físicos. Experiências em Ensino de Ciências, v. 11, n. 2, p. 60-105, 2016.

CUNHA, M. B. Jogos no ensino de química: considerações teóricas para sua utilização em sala de aula. Química Nova na Escola, São Paulo, v. 34, n. 2, p. 92-98, 2012.

DETERDING, S. et al. From Game Design Elements to Gamefulness: Defining "Gamification". International Academic MindTrek Conference - Envisioning Future Media Environments. Tampere: Annals..., 2011

DUARTE, M. C. Analogias na educação em ciências: contributos e desafios. Investigações em Ensino de Ciências, v. 10, n. 1, p. 7-29, 2005.

ERENLI, K. The Impact of Gamification: recommending education scenarios. International Journal of Engineering \& Technology, v. 8, n. spec., p. 15-21, 2013.

FERREIRA, L. N. A.; QUEIROZ, S. L. Características discursivas de artigos de divulgação científica relacionados à química. Revista Electrónica de Enseñanza de las Ciencias, v. 11, n.1 p. 21-42, 2012.

FERREIRA, M. C.; CARVALHO, L. M. O. O jogo como avaliação formativa: questões sobre o conceito de pressão. VIII Encontro de Pesquisa em Ensino de Física (EPEF). Águas de Lindóia: Anais..., 2002.

FREITAS, L. C. Avaliação: construindo o conceito. Ciência \& Ensino, v. 3, 16-19, 1997.

FREITAS, R. L., FURLAN, A. L. D.; KUNZE, J. C. Uso de jogos como ferramenta didática no ensino de botânica. X Congresso Nacional de Educação - EDUCERE. Curitiba: Anais..., 2011.

JANN, P. N.; LEITE, M. F. Jogo do DNA: um instrumento pedagógico para o ensino de ciências e biologia. Ciências \& Cognição, Rio de Janeiro, v. 15, n.1, p. 282-293, 2010.

KAPP, K. M., The gamification of learning and instruction: Game-based methods and strategies for training and education. San Francisco: John Wiley \& Sons, 2012.

KAPP, K. M., BLAIR, L.; MESCH, R. The Gamification of Learning and Instruction Fieldbook. San Francisco: Wiley, 2014.

KISHIMOTO, T. M. Jogo, Brinquedo, Brincadeira e a Educação. São Paulo: Cortez, 1996. 
DOI: $10.12957 /$ e-mosaicos.2020.44414

LIMA, M. F. C. Brincar e aprender: o jogo como ferramenta pedagógica no ensino de Física - Guia para o Professor. Rio de Janeiro: UFRJ/IF, 2011.

LIMA, M. F. C.; SOARES, V. Brincar para construir o conhecimento: jogo e cinemática. Física na Escola, v. 11, n. 1, p. 24-26, 2010.

MATALLAOUI, A., HANNER, N.; ZARNEKOW, R. Introduction to Gamification:

Foundation and Underlying Theories. In: STIEGLITZ, S. et al. (ed.). Gamification: using game elements in serious contexts. Cham: Springer, 2017. p. 3-18.

MAYER, R. E. Multi-media learning. $2^{\mathrm{a}}$ ed. Cambridge: Cambridge University Press, 2009.

NAFFAH NETO, A. Psicodrama: descolonizando o imaginário. São Paulo: Brasiliense, 1979.

NICHOLSON, S. A Recipe for Meaningful Gamification. In: REINER, T.; WOOD, L. C. (ed.) Gamification in Education and Business. Cham: Springer, 2015. p. 1-20.

PELLING, N. The (short) prehistory of gamefication. 2011. Disponível em: https://goo.gl/H1WK7k, acesso em jun. 2015.

PRENSKY, M. Digital Game-Based Learning. New-York: McGraw-Hill, 2001.

PRICE, R. V. Computer-aided instruction: a guide for authors. Pacific Grove, CA: Brooks/ Cole Publishing Company, 1990.

SILVA, A. C.; FORTUNATO, I. Jogos na formação inicial de professores de física: mapeando a produção bibliográfica nacional. Revista Internacional de Formação de Professores, v. 1, n. 4, p. 56-63, 2016.

SILVA, J. B.; SALES, G. L. Gamificação aplicada no ensino de Física: um estudo de caso no ensino de óptica geométrica. Acta Scientiae, v. 19, n. 5, p. 782-798, 2017.

SILVA, L. L.; TERRAZZAN, E. A. As analogias no ensino de conteúdos conceituais, procedimentais e atitudinais em aulas de Física do Ensino Médio. Experiências em Ensino de Ciências, v. 6, n. 1, p. 133-154, 2011.

SOARES, M. Jogos para o ensino de química: teoria, métodos e aplicações. Brasília: Ex-Libris, 2008.

STUDART, N. Simulação, Games e Gamificação no Ensino de Física. XXI Simpósio Nacional de Ensino de Física (SNEF). Uberlândia: Anais... 2015.

TEICHNER, O.; FORTUNATO, I. Refletindo sobre a Gameficação e suas possibilidades na educação. Revista Brasileira de Iniciação Científica, Itapetininga, v. 2, n. 3, p. 102-111, 2015. 
DOI: $10.12957 /$ e-mosaicos.2020.44414

ZANETIC, J. Física e Cultura. Ciência e Cultura, v. 57, n. 21, p. 21-24, 2005.

ZANOTELLO, M.; ALMEIDA, M. J. P. M. Produção de sentidos e possibilidades de mediação na Física do ensino médio: leitura de um livro sobre Isaac Newton. Revista Brasileira de Ensino de Física, v. 29, n. 3, 437-446, 2007.

Recebido em 05 de agosto de 2019

Aceito em 27 de setembro de 2019

A e-Mosaicos Revista Multidisciplinar de Ensino, Pesquisa, Extensão e Cultura do Instituto de Aplicação Fernando Rodrigues da Silveira (CAp-UERJ) está licenciada com uma Licença Creative Commons - Atribuição-NãoComercial 4.0 Internacional.

Os direitos autorais de todos os trabalhos publicados na revista pertencem ao(s) seu(s) autor(es) e coautor(es), com o direito de primeira publicação cedido à e-Mosaicos.

Os artigos publicados são de acesso público, de uso gratuito, com atribuição de autoria obrigatória, para aplicações de finalidade educacional e não-comercial, de acordo com o modelo de licenciamento Creative Commons adotado pela revista. 